\title{
Characterization of a Candida albicans Mutant Defective in All MAPKs Highlights the Major Role of Hog1 in the MAPK Signaling Network
}

\author{
Inês Correia ${ }^{1, *}$, Duncan Wilson ${ }^{2}$, Bernhard Hube ${ }^{3,4}{ }^{(\mathbb{C}}$ and Jesús Pla ${ }^{5, *}$ \\ 1 iBiMED-Institute of Biomedicine, Department of Medical Sciences, University of Aveiro, Agra do Crasto, \\ 3810-193 Aveiro, Portugal \\ 2 Medical Research Council Centre for Medical Mycology, School of Biosciences, University of Exeter, \\ Exeter EX4 4QD, UK; Duncan.Wilson@exeter.ac.uk \\ 3 Department of Microbial Pathogenicity Mechanisms, Leibniz Institute for Natural Product Research and \\ Infection Biology-Hans-Knoell-Institute, Beutenbergstraße 11A, 07745 Jena, Germany; \\ bernhard.hube@hki-jena.de \\ 4 Institute of Microbiology, Friedrich Schiller University, Neugasse 25, 07743 Jena, Germany \\ 5 Departamento de Microbiología y Parasitología-IRYCIS, Facultad de Farmacia, Universidad Complutense de \\ Madrid, Avda. Ramón y Cajal s/n, 28040 Madrid, Spain \\ * Correspondence: inescorreia@ua.pt (I.C.); jpla@ucm.es (J.P.); \\ Tel.: +351-234-370-213 (I.C.); +34-913-941-617 (J.P.)
}

Received: 15 September 2020; Accepted: 14 October 2020; Published: 17 October 2020

\begin{abstract}
The success of Candida albicans as a pathogen relies on its ability to adapt and proliferate in different environmental niches. Pathways regulated by mitogen-activated protein kinases (MAPKs) are involved in sensing environmental conditions and developing an accurate adaptive response. Given the frequent cooperative roles of these routes in cellular functions, we have generated mutants defective in all combinations of the four described MAPKs in C. albicans and characterized its phenotype regarding sensitiveness to specific drugs, morphogenesis and interaction with host immune cells. We demonstrate that all MAPKs are dispensable in this yeast as a mutant defective in Cek1, Cek2, Mkc1 and Hog1 is viable although highly sensitive to oxidative and osmotic stress, displaying a specific pattern of sensitivity to antifungals. By comparing its phenotype with single, double and triple combinations of MAPK-deletion mutants we were able to unveil a Cek1-independent mechanism for Hog1 resistance to Congo red, and confirm the predominant effect of Hog1 on oxidative and osmotic adaptation. The quadruple mutant produces filaments under non-inducing conditions, but is unable to develop chlamydospores. Furthermore, cek1 cek $2 m k c 1$ hog 1 cells switch to the opaque state at high frequency, which is blocked by the ectopic expression of HOG1 suggesting a role of this kinase for phenotypic switching.
\end{abstract}

Keywords: MAPK; osmotic stress; filamentation; chlamydospore; cell wall; oxidative stress; fungal virulence

\section{Introduction}

Candida albicans is a pathogenic fungus frequently causing infection in humans. However, 30 to $70 \%$ of the human population is colonized by this microorganism in the vaginal and gastrointestinal tract without any symptoms. Only when the host immune system is compromised, when the microbiota is disturbed or when the epithelial barrier integrity is damaged, C. albicans may proliferate inside or outside these niches and can, in severe cases, develop invasive infections that are associated with a high mortality rate [1-3]. 
An important feature of the biology of $C$. albicans is its ability to change its morphology from yeast-to-hypha in response to nutritional and environmental factors, such as temperature $\left(37^{\circ} \mathrm{C}\right)$, $\mathrm{pH}(>7)$, or the presence of $\mathrm{N}$-acetylglucosamine or serum. The filamentous form has been considered for a long time as the more invasive morphology of the fungus as mutants unable to filament under in vitro conditions (such as efg1 and cph1) showed impaired virulence in animal models [4]. However, both morphologies are important for infection: yeast cells for fungal dissemination and hyphae for tissue invasion, host cell damage and immune evasion [5-8].

Under specific laboratory conditions such as absence of light, glucose limitation, low temperature and microaerophilia $[9,10]$, C. albicans can also form thick-walled structures called chlamydospores. Although their biological function is unknown, they have been proposed to play a role in persistence (survival under adverse conditions) rather than dissemination [11-13]. Different genes were shown to be required for chlamydospore formation, including EFG1 and HOG1 [14,15], and specific markers have been identified [16].

For decades, C. albicans was thought to be an asexual yeast. However, under certain circumstances, mating is possible [17-19]. This requires conversion of the mating-type locus (MTL a/ $\alpha$ ) to a/a or $\alpha / \alpha$ and an epigenetic switch called white-opaque switching, a spontaneous and reversible change from the ubiquitous white type of cells to the opaque phenotype. This triggers a pheromone-mediated process that can ultimately result in cell fusion [17-19]. White-opaque switching has been the subject of intensive study in recent years [20] as mating is a source of genetic variability with potential implications on cells adaptation to new environments [21-23]. Notably, gene flow has recently been detected between C. albicans isolates [24].

All these morphological transitions, as well as the adaptation to environmental stress, are tightly controlled by different signaling pathways. In C. albicans, four mitogen-activated protein kinases (MAPKs) mediate signal transduction. Hog1 regulates adaptation to oxidative and osmotic stress [15,25,26], Mkc1 is involved in cell wall construction (cell integrity pathway) [27] and invasion of solid surfaces [28], Cek1 is implicated in cell wall biogenesis [29-31], while Cek2 is involved in mating [32]. However, the interconnections among these pathways are frequent and increase the plasticity and complexity of the response [33-35]. For example, Mkc1, like Hog1, is also phosphorylated in response to oxidative stress [36]. Cek1 and Cek2 are both important for mating and cell wall damage response [31,37]. Cek1 and Hog1 MAPKs play complementary roles on cell wall biogenesis and in chlamydospore formation: the resistance of a hog1 mutant to Congo red, calcofluor white and nikkomycin Z [25] seems to be caused by Cek1 hyperactivation and the inability of hog 1 to form chlamydospores is suppressed by the additional deletion of upstream elements of the Cek1 pathway such as CST20 or HST7 [38]. All these examples illustrate the intricacy and crosstalk among these routes and the cooperative and counterbalancing role that they have in the cell.

To further elucidate the crosstalk between all these central MAPK signaling networks, we have generated a strain deprived of the four main MAPKs. Here, we characterized this strain and assessed the importance of each MAPK in specific stress conditions as well as in the morphogenetic programs of C. albicans.

\section{Materials and Methods}

\subsection{Strain Construction and Growth Conditions}

C. albicans strains used in this work are listed in Table 1. All strains from the MAPK mutants collection were derived from the laboratory-adapted CAI4 and were obtained using the URA3-blaster protocol [39]. HOG1, CEK2 and MKC1 deletions were made as previously described $[26,27,38]$ and correct disruptions were confirmed by Southern blot (Figure S1). MAPK's ectopic expression was achieved by integration at the ADH1 locus of the plasmid pNRU [37]. CEK1, CEK2, MKC1 and HOG1 ORFs were amplified by PCR from the clinical isolate SC5314. The correct expression of these 
epitope-labelled alleles was verified by Western blots against the myc epitope. The CAI4 parental strain CAF2, which is heterozygous for URA3, has been used as the background wild type.

Table 1. Strains of C. albicans used in this work.

\begin{tabular}{|c|c|c|}
\hline Strain Name & Background Strain and Genotype & Source \\
\hline SC5314 (wt) & Clinical isolate & [40] \\
\hline CAF2 (wt) & 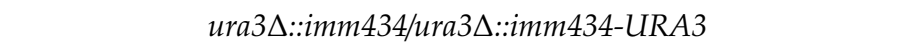 & [39] \\
\hline CAI4 & ura3s::imm434/ura3s::imm434 & [39] \\
\hline cek1 & 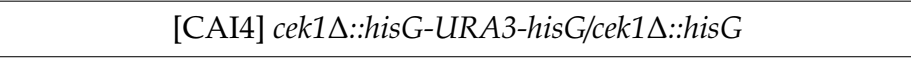 & {$[41]$} \\
\hline cek2 & [CAI4] cek2::cat-URA3-cat/cek2::cat & [37] \\
\hline$m k c 1$ & [CAI4] mkc1::hisG-URA3-hisG/mkc1::hisG & [27] \\
\hline hog1 & [CAI4] hog1::hisG-URA3-hisG/hog1::hisG & [42] \\
\hline cek1 cek2 & [CAI4] cek1::hisG/cek1::hisG cek2::cat-URA3-cat/cek2::cat & [37] \\
\hline cek1 mkc1 & [CAI4] cek1::hisG/cek1::hisG mkc1::hisG-URA3-hisG/mkc1::hisG & [37] \\
\hline cek1 hog1 & $\begin{array}{l}\text { [CAI4] cek1::hisG/cek1::hisG hog1::hisG/hog1::hisG ARD1/ard1::FRT } \\
\text { SAP2pr-FLPURA3 }\end{array}$ & [43] \\
\hline$h o g 1 m k c 1$ & [CAI4] hog1::hisG/hog1::hisG mkc1::hisG-URA3-hisG/mkc1::hisG & [37] \\
\hline cek2 hog1 & [CAI4] cek2::cat/cek2::cat hog1::hisG-URA3-hisG/hog1::hisG & {$[37]$} \\
\hline cek2 $m k c 1$ & [CAI4] cek2::cat/cek2::cat mkc1::hisG-URA3-hisG/mkc1::hisG & [37] \\
\hline cek1 cek2 mkc1 & $\begin{array}{c}\text { [CAI4] cek1::hisG/cek1::hisG cek2::cat/cek2::cat } \\
\text { mkc1::hisG-URA3-hisG/mkc1::hisG }\end{array}$ & This work \\
\hline cek1 cek2 hog1 & $\begin{array}{l}\text { [CAI4] cek1::hisG/cek1::hisG cek2::cat/cek2::cat } \\
\text { hog1::hisG-URA3-hisG/hog1::hisG }\end{array}$ & This work \\
\hline cek1 mkc1 hog1 & $\begin{array}{c}\text { [CAI4] cek1::hisG/cek1::hisG mkc1::hisG/mkc1::hisG } \\
\text { hog1::hisG-URA3-hisG/hog1::hisG }\end{array}$ & This work \\
\hline hog1 mkc1 cek2 & $\begin{array}{c}\text { [CAI4] hog1::hisG/hog1::hisG mkc1::hisG/mkc1::hisG } \\
\text { cek2::cat-URA3-cat/cek2::cat }\end{array}$ & This work \\
\hline cek1 cek 2 hog1 mkc1 & $\begin{array}{c}\text { [CAI4] cek1::hisG/cek1::hisG cek2::cat/cek2::cat } \\
\text { hog1::hisG/hog1::hisG mkc1::hisG-URA3-hisG/mkc1::hisG }\end{array}$ & This work \\
\hline cek1 cek 2 mkc1 hog1 & $\begin{array}{c}\text { [CAI4] cek1::hisG/cek1::hisG cek2::cat/cek2::cat } \\
\text { mkc1::hisG/mkc1::hisG hog1::hisG-URA3-hisG/hog1::hisG }\end{array}$ & This work \\
\hline $\begin{array}{l}\text { cek1 cek2 mkc1 hog1 } \\
\text { pNRU-CEK1 }\end{array}$ & $\begin{array}{c}\text { [CAI4] cek1::hisG/cek1::hisG cek2::cat/cek2::cat } \\
\text { mkc1::hisG/mkc1::hisG hog1::hisG/hog1::hisG } \\
\text { ADH1/adh1::tTA pTet-CEK1-myc-URA3 }\end{array}$ & This work \\
\hline $\begin{array}{l}\text { cek1 cek2 mkc1 hog1 } \\
\text { pNRU-CEK2 }\end{array}$ & $\begin{array}{c}\text { [CAI4] cek1::hisG/cek1::hisG cek2::cat/cek2::cat } \\
\text { mkc1::hisG/mkc1::hisG hog1::hisG/hog1::hisG } \\
\text { ADH1/adh1::tTA pTet-CEK2-myc-URA3 }\end{array}$ & This work \\
\hline $\begin{array}{l}\text { cek1 cek2 mkc1 hog1 } \\
\text { pNRU-MKC1 }\end{array}$ & $\begin{array}{c}\text { [CAI4] cek1::hisG/cek1::hisG cek2::cat/cek2::cat } \\
\text { mkc1::hisG/mkc1::hisG hog1::hisG/hog1::hisG } \\
\text { ADH1/adh1::tTA pTet-MKC1-myc-URA3 }\end{array}$ & This work \\
\hline $\begin{array}{l}\text { cek1 cek2 mkc1 hog1 } \\
\text { pNRU-HOG1 }\end{array}$ & $\begin{array}{l}\text { [CAI4] cek1::hisG/cek1::hisG cek2::cat/cek2::cat } \\
\text { mkc1::hisG/mkc1::hisG hog1::hisG/hog1::hisG } \\
\text { ADH1/adh1::tTA pTet-HOG1-myc-URA3 }\end{array}$ & This work \\
\hline
\end{tabular}

Yeast strains were routinely grown at $37^{\circ} \mathrm{C}$ in yeast extract-peptone-dextrose (YPD) medium ( $2 \%$ glucose, $2 \%$ peptone, $1 \%$ yeast extract) and short term stored at $4{ }^{\circ} \mathrm{C}$. Analysis of strains' sensitivity to different agents was performed through drop tests, by spotting $5 \mu \mathrm{L}$ of tenfold serial dilutions of overnight grown cultures on solid YPD plates supplemented (or not, control) with the indicated compound at the indicated concentration. Plates were incubated for $48 \mathrm{~h}$ at $37^{\circ} \mathrm{C}$ (unless otherwise 
stated) and scanned for Figure assembly. For analysis of yeast sensitivity to antifungals, cells from overnight cultures grown at $37^{\circ} \mathrm{C}$ were inoculated in 96-well plates at O.D. (Optical Density) $=0.025$ in medium supplemented with increased concentrations of the compound and incubated statically for $24 \mathrm{~h}$ at $37^{\circ} \mathrm{C}$. The final O.D. of each strain in the presence of different compound concentrations was measured and normalized to the final O.D. reached by the positive control (strains inoculated in medium without the antifungal).

\subsection{Interaction Assays with Murine Macrophages}

C. albicans killing by murine macrophages from cell line RAW 264.7 was performed in 24-well plates. One million immune cells were co-incubated with yeast cells (1 yeast cell:20 phagocytes) for $4 \mathrm{~h}$ at $37{ }^{\circ} \mathrm{C}$ and $5 \% \mathrm{CO}_{2}$. After phagocyte lysis with water and use of a scrapper to recover adhered cells, serial dilutions were made and spread over YPD agar plates for determinations of CFUs (Colony Forming Units). Plates were incubated for $24 \mathrm{~h}$ at $37^{\circ} \mathrm{C}$. The percentage of killing for each strain was expressed as the reduction in CFUs from yeast co-cultures with macrophages versus cultures containing only yeast cells without phagocytes made simultaneously. A one-way ANOVA multiple comparison test was used to assess significance related to CAF2.

\subsection{Morphogenesis Assays}

Hyphal formation in liquid medium was induced by serum $100 \%$ or $5 \%: 10^{6}$ cells from overnight grown cultures were inoculated in YPD medium supplemented or not with serum and grown at $30^{\circ} \mathrm{C}$. Cells were microscopically observed after $5 \mathrm{~h}$ and $24 \mathrm{~h}$ of growth. Pictures were taken and processed likewise. To induce chlamydospore formation, 25 to 50 cells from a stationary culture at $37^{\circ} \mathrm{C}$ were inoculated in corn meal agar (CMA) supplemented with $1 \%$ Tween 80 and covered by coverslips to induce microaerophilia. The samples were incubated in the dark at $24^{\circ} \mathrm{C}$ for up to 10 days. Chlamydospores were observed at day 4 and 7. White-opaque switching of C. albicans strains was induced by growing cells on solid media at room temperature $\left(<21^{\circ} \mathrm{C}\right)$ for at least three days. Strains previously grown at $30^{\circ} \mathrm{C}$ were spread onto YPD plates supplemented with phloxine B $(50 \mu \mathrm{g} / \mathrm{mL})$ and around 400 cells were analyzed. White-opaque reversibility was studied by incubating opaque cells at different temperatures on solid medium (YPD-phloxine B).

\section{Results}

\subsection{A Strain Lacking CEK1, CEK2, MKC1 and HOG1 Is Viable but Highly Sensitive to Osmotic and Oxidative Stress}

Previous studies by our group and others have revealed the crucial role that efficient MAPK-mediated signaling plays in response to stress. In order to understand and uncover putative crosstalk between MAPKs, we expanded our previously described collection of single- and double-MAPK mutants $[34,37]$ by deleting the remaining MAPKs in order to generate all combinations of triple mutants and a strain defective in all four described MAPKs in this fungus. This strain is viable and does not display evident growth defects under standard laboratory conditions. We analyzed this strain in the presence of specific compounds known to activate the pathways and compared its behavior with strains that have only one functional MAPK, either endogenous or ectopically integrated, using standard drop assays on solid media. The results are shown in Figure 1 and the main findings are the following. First, the quadruple mutant showed high sensitivity to both osmotic and oxidative stress. Second, none of the mutants with an intact HOG pathway were found to be sensitive to $\mathrm{NaCl}$ or Sorbitol (Figure 1A) reinforcing the idea that Hog1 is the key kinase for adaptation to osmotic stress; in fact, the sensitivity of the cek1 cek $2 m k c 1$ hog 1 mutant to $\mathrm{NaCl}$ was completely rescued to wild-type levels by integration of a plasmid carrying HOG1. Third, the cek1 cek2 mkc1 hog1 mutant strain showed the same phenotype as the one observed for all strains defective in both Cek1 and Hog1 kinases, which is a hypersensitivity to osmotic stress (Figure 1A, $\mathrm{NaCl} 1 \mathrm{M}$ ) $[37,44]$ and the additional 
deletion of other kinases did not alter the levels of growth inhibition. Accordingly, the additional deletion of CEK1 aggravates the growth defects of a hog $1 m k c 1$ cek 2 strain which is by itself sensitive, confirming that Cek1 plays a crucial role in hog1 defective strains to survive under hyperosmotic conditions. Interestingly, all mutants from the collection lacking HOG1 were found to be similarly sensitive to oxidants (Figure 1B), strongly supporting the idea that Hog1 is the main MAPK responsible for C. albicans survival under these conditions.

A

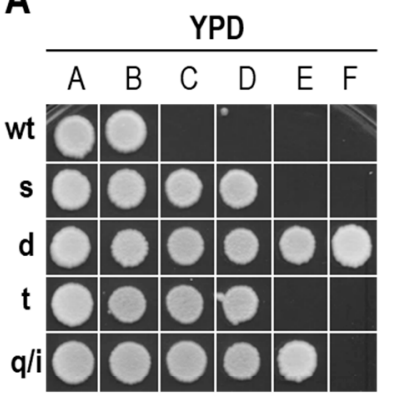

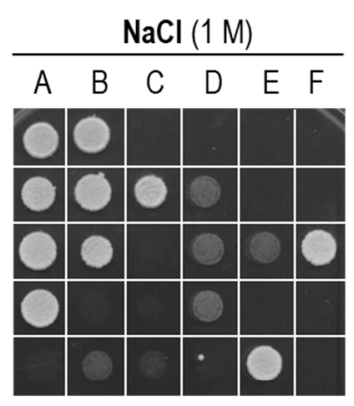

$\mathrm{NaCl}(1.5 \mathrm{M})$

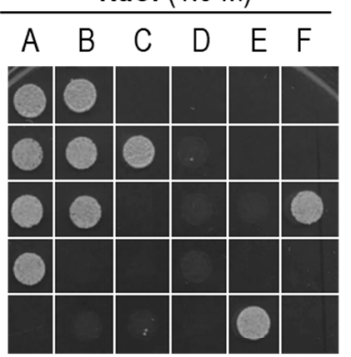

Sorbitol (2 M)

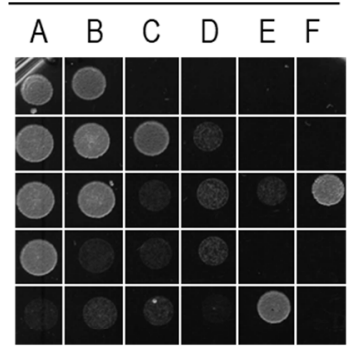

B

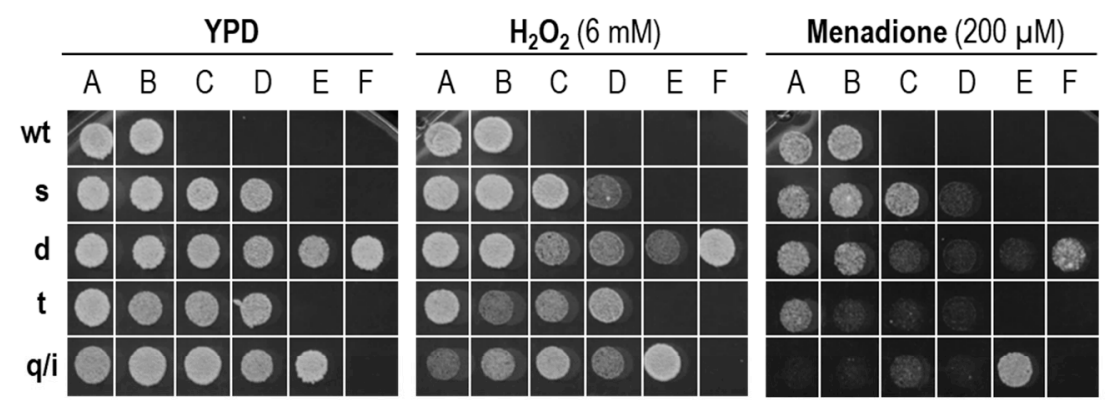

\begin{tabular}{|c|c|c|c|c|c|c|}
\hline & $A$ & B & C & $D$ & $E$ & $F$ \\
\hline wt & SC5314 & CAF2 & & & & \\
\hline $\mathbf{s}$ & cek1 & cek2 & $m k c 1$ & hog1 & & \\
\hline d & cek1 cek2 & cek1 mkc1 & cek1 hog1 & hog1 mkc1 & cek2 hog1 & cek2 mkc1 \\
\hline$t$ & $\begin{array}{c}\text { cek1 cek2 } \\
m k c 1\end{array}$ & $\begin{array}{c}\text { cek1 cek2 } \\
\text { hog1 }\end{array}$ & $\begin{array}{c}\text { cek1 mkc1 } \\
\text { hog1 }\end{array}$ & \begin{tabular}{|c|} 
hog1 $\mathrm{mkc1}$ \\
cek2
\end{tabular} & & \\
\hline$q / i$ & $\begin{array}{c}\text { cek1 cek2 } \\
\text { mkc1 hog1 }\end{array}$ & $\begin{array}{c}\text { cek1 cek2 } \\
\text { mkc1 hog1 } \\
\text { pNRU-CEK1 }\end{array}$ & $\begin{array}{c}\text { cek1 cek2 } \\
\text { mkc1 hog1 } \\
\text { pNRU-CEK2 }\end{array}$ & $\begin{array}{c}\text { cek1 cek2 } \\
\text { mkc1 hog1 } \\
\text { pNRU-MKC1 }\end{array}$ & $\begin{array}{c}\text { cek1 cek2 } \\
\text { mkc1 hog1 } \\
\text { pNRU-HOG1 }\end{array}$ & \\
\hline
\end{tabular}

Figure 1. Comparative growth of mitogen-activated protein kinase (MAPK) mutants in the presence of osmotic and oxidative stress. $10^{4}$ cells from a set of MAPK mutants grown overnight at $37^{\circ} \mathrm{C}$ in yeast extract-peptone-dextrose (YPD) were spotted on solid agar plates of YPD medium supplemented or not (YPD) with $\mathrm{NaCl}$, sorbitol, $\mathrm{H}_{2} \mathrm{O}_{2}$ or menadione at the indicated concentrations. Plates were incubated at $37^{\circ} \mathrm{C}$ and pictures were taken at $24 \mathrm{~h}(\mathbf{B})$ or $48 \mathrm{~h}(\mathbf{A})$. A diagram of the strains' locations within the plate is shown. wt: wild type; s: single mutants; d: double mutants; $t$ : triple mutants; q: quadruple mutant; i: quadruple mutants with an ectopically integrated MAPK.

Interaction studies of kinase mutants with immune cells have revealed an increased susceptibility of hog1 to murine macrophage killing (probably due to the formation of reactive oxygen species (ROS)), as well as a slight resistance of $c e k 1$ with no altered susceptibility of $c e k 2$ and $m k c 1$ compared to wild-type controls [43]. We therefore analyzed the behavior of our mutant collection when confronted with macrophages. For this, the mutants were individually incubated with a confluent monolayer of RAW 264.7 cell line macrophages infected at MOI 1:20 (yeast:macrophages) for $4 \mathrm{~h}$.

We observed an increased susceptibility of all triple mutants compared to the strains defective in only two kinases and, in turn, an increased susceptibility for the quadruple mutant as compared to the triple deletion mutants (Figure 2). In fact, the absence of all MAPKs led to a 2.8-fold increase in C. albicans mutant cell susceptibility to this macrophage cell line. Interestingly, susceptibility to 
macrophages was not exclusive to hog 1 mutants as cek1 cek2, cek1 mkc1 and particularly cek1 cek2 mkc1 also showed an increased vulnerability to macrophage-mediated killing.

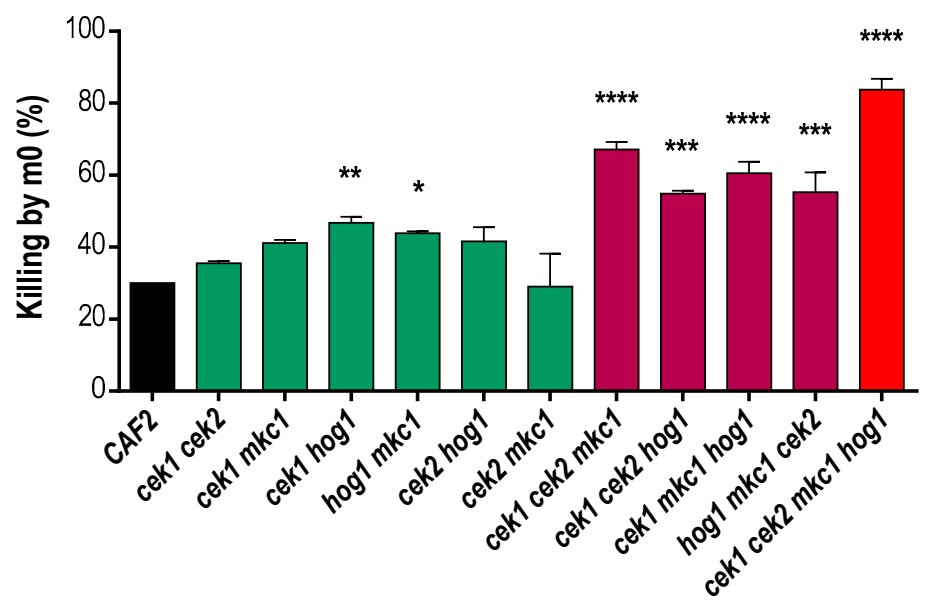

Figure 2. Susceptibility of MAPK mutants to macrophage-mediated killing. Yeast cells were added to a confluent monolayer of murine macrophages from cell line RAW 264.7 at MOI 1:20 (yeast:m0) and co-incubated for $4 \mathrm{~h}$ at $37^{\circ} \mathrm{C}$ and $5 \% \mathrm{CO}_{2}$. Killing percentages were assessed after CFU counting of fungal cells obtained upon interaction and related to fungal cells assayed without macrophages (positive control-0\% killing). All strains were normalized to the wild type (CAF2) with a given value of $30 \%$ killing. Error bars represent the standard deviation of duplicates. ${ }^{*} p<0.05 ;{ }^{* *} p<0.01 ;{ }^{* * *} p<0.001$; **** $p<0.0001$ (one-way ANOVA, multiple comparison tests related to CAF2).

To extend our analysis on the mutants' susceptibility to stress conditions, we assessed their growth inhibition in the presence of amphotericin B and fluconazole which directly or indirectly target the fungal cell membrane. Amphotericin B binds to ergosterol causing permeability alterations and eventually pore formation, while fluconazole inhibits the ergosterol biosynthesis leading to the accumulation of toxic sterol intermediates and cell membrane stress. Despite the fact that these antifungals act through different mechanisms of action and with different outcomes (amphotericin B is fungicidal while fluconazole is fungistatic) they both induce ROS production in C. albicans [45-47]. Our data support these results as all strains with a HOG1 deletion were found to be sensitive to amphotericin B (Figure 3).

While the deletion of $M K C 1$ (in any background) did not affect the susceptibility to amphotericin B, strains defective in CEK1 and/or CEK2 showed a reduced susceptibility to the compound. The additional deletion of HOG1 in mutants lacking CEK1 and/or CEK2, however, impaired their growth. Therefore, the quadruple mutant was highly sensitive to amphotericin B, which was reverted by HOG1 ectopic expression to the levels obtained for the wild type [48]. Hog1 also seems to be crucial for C. albicans adaptation to fluconazole. Amongst the single mutants, hog1 showed the most significant growth defect and all other hog1-null strains displayed a clear sensitive phenotype (Figure 3). Altogether, these results indicate that $C$. albicans adaptation to osmotic, oxidative and antifungal drug conditions is highly dependent on the Hog1 kinase while other MAPKs play secondary roles for these conditions. 


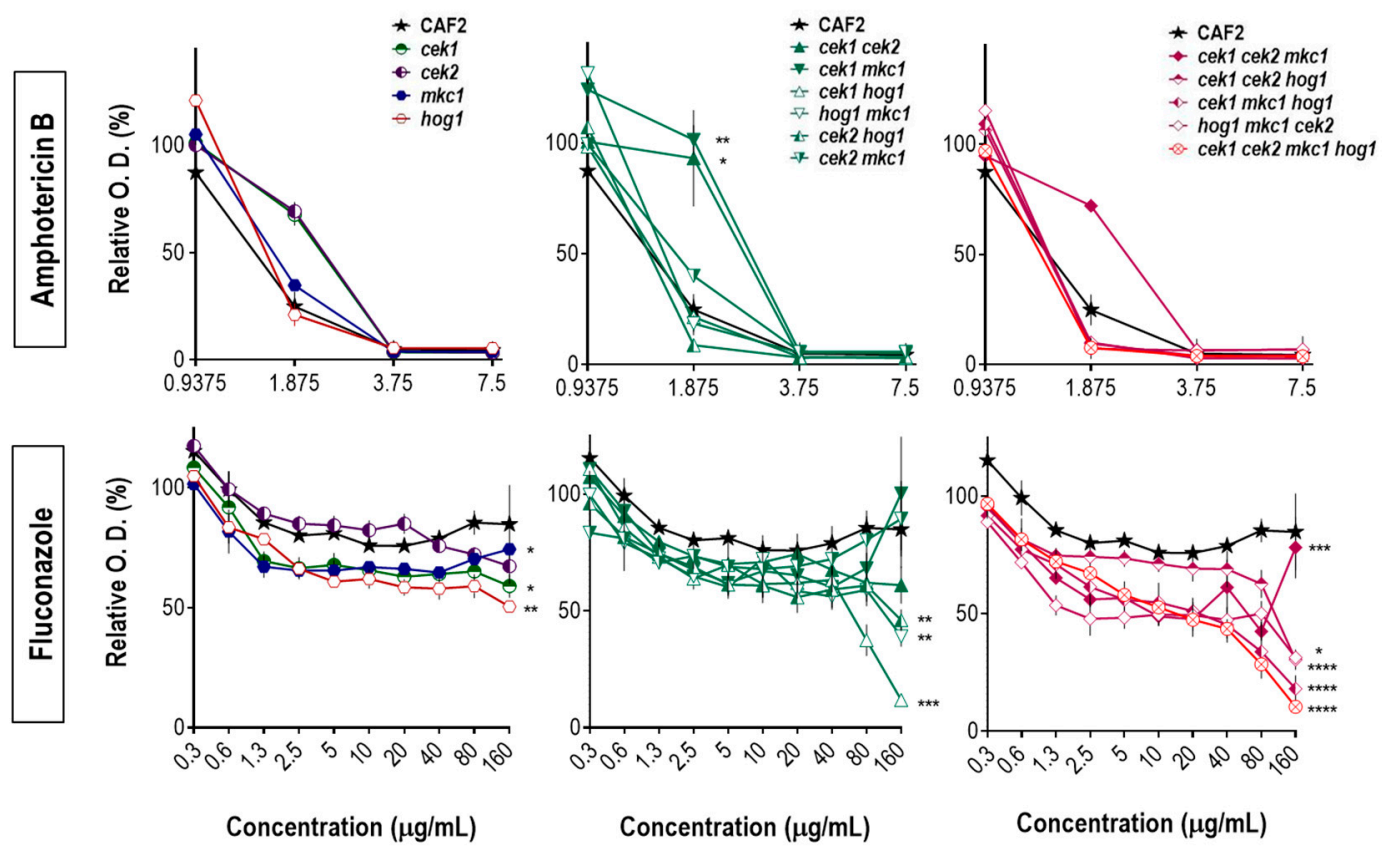

Figure 3. Sensitivity of MAPK mutants to antifungal treatment. Cells from cultures grown overnight at $37^{\circ} \mathrm{C}$ were inoculated in a 96-well plate at final O.D. $=0.025\left(10^{5}\right.$ cells $)$. Amphotericin B or fluconazole was added to the plates in increasing 2-fold concentrations ranging from $0.030 \mu \mathrm{g} / \mathrm{mL}$ to $15 \mu \mathrm{g} / \mathrm{mL}$ (shown only $0.94 \mu \mathrm{g} / \mathrm{mL}$ to $7.5 \mu \mathrm{g} / \mathrm{mL}$-amphotericin B) or $0.32 \mu \mathrm{g} / \mathrm{mL}$ to $160 \mu \mathrm{g} / \mathrm{mL}$ (fluconazole). Inoculated plates were incubated at $37^{\circ} \mathrm{C}$ for $24 \mathrm{~h}$ prior to O.D. assessment. Each strain has been normalized to its positive control (without antifungal) and the growth inhibition curve is shown. Error bars represent the standard error of the mean from two independent experiments. ${ }^{*} p<0.05$; ${ }^{* *} p<0.01 ;{ }^{* *} p<0.001 ;{ }^{* * *} p<0.0001$ (two-way ANOVA multiple comparison tests related to CAF2).

\subsection{Hog1 Resistance to Cell Wall Interfering Drugs Is Not Exclusively Due to Cek1 Hyperactivation}

Signaling pathways mediated by MAPKs have also a crucial role in the biogenesis and maintenance of the fungal cell wall. We therefore analyzed our deletion mutant collection for their behavior in the presence of Congo red. While the $m k c 1$ and cek2 mutants have been reported to show sensitivity [27,37], the triple mutant hog1 $m k c 1$ cek 2 showed a resistant phenotype (Figure 4A) therefore resembling the hog1 single mutant [25]. This is further evidence that Hog1 is the dominant MAPK governing stress responses in C. albicans.

However, the additional deletion of CEK1 (leading to the quadruple mutant) increased the sensitivity of the triple mutant. This observation is further confirmed by the ectopic integration of CEK1 in the cek1 cek2 mkc1 hog1 strain, which restored the phenotype. This result is in line with the previous hypothesis that the hog1 resistant phenotype to cell wall damage was mainly due to Cek1 hyperactivation [38]. Nevertheless, other elements or mechanisms besides Cek1 hyperactivation may be implicated in the resistance of hog 1 cells to Congo red as the deletion of HOG1 alleviates the hypersensitivity caused by the absence of a functional Cek1/Cek2 and Mkc1 pathways. As shown in Figure 4B, the triple mutant cek1 cek2 $m k c 1$, similar to our previous observation with cek1 $m k c 1$ and cek $2 m k c 1$ strains [37], is extremely sensitive to Congo red, while cek1 cek2 $m k c 1$ hog 1 cells were not as sensitive and were even able to proliferate after prolonged incubation times at higher concentrations of stressing agents. As expected, the ectopic expression of HOG1 increased the sensitivity of the quadruple mutant to the levels of its corresponding strain cek1 cek2 mkc1. 
A

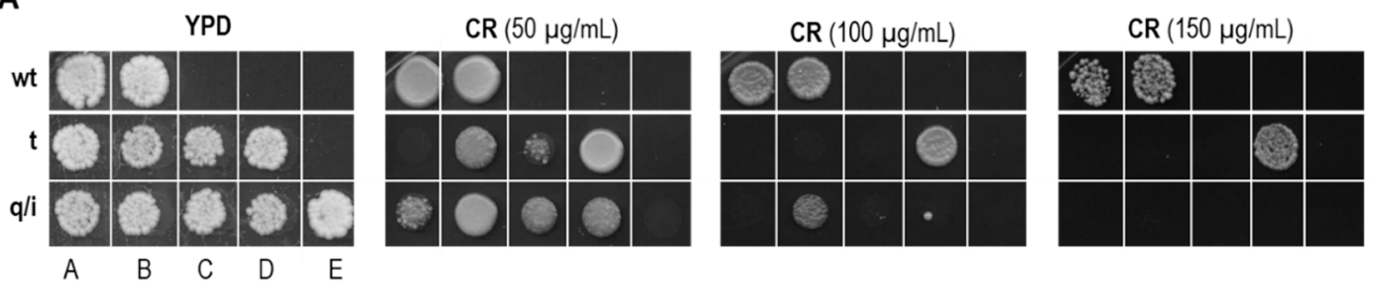

\begin{tabular}{|c|c|c|c|c|c|}
\hline & A & B & C & D & E \\
\hline wt & sc5314 & CAF2 & & & \\
\hline $\mathrm{t}$ & $\begin{array}{c}\text { cek1 cek2 } \\
m k c 1\end{array}$ & $\begin{array}{c}\text { cek1 cek2 } \\
\text { hog1 }\end{array}$ & $\begin{array}{c}\text { cek1 mkc1 } \\
\text { hog1 }\end{array}$ & $\begin{array}{c}\text { hog1 mkc1 } \\
\text { cek2 }\end{array}$ & \\
\hline $\mathrm{q} / \mathrm{i}$ & $\begin{array}{c}\text { cek1 cek2 } \\
\text { mkc1 hog1 }\end{array}$ & $\begin{array}{c}\text { cek1 cek2 } \\
\text { mkc1 hog1 } \\
\text { pNRU-CEK1 }\end{array}$ & $\begin{array}{c}\text { cek1 cek2 } \\
\text { mkc1 hog1 } \\
\text { pNRU-CEK2 }\end{array}$ & $\begin{array}{c}\text { cek1 cek2 } \\
\text { mkc1 hog1 } \\
\text { pNRU-MKC1 }\end{array}$ & $\begin{array}{c}\text { cek1 cek2 } \\
\text { mkc1 hog1 } \\
\text { pNRU-HOG1 }\end{array}$ \\
\hline
\end{tabular}

B

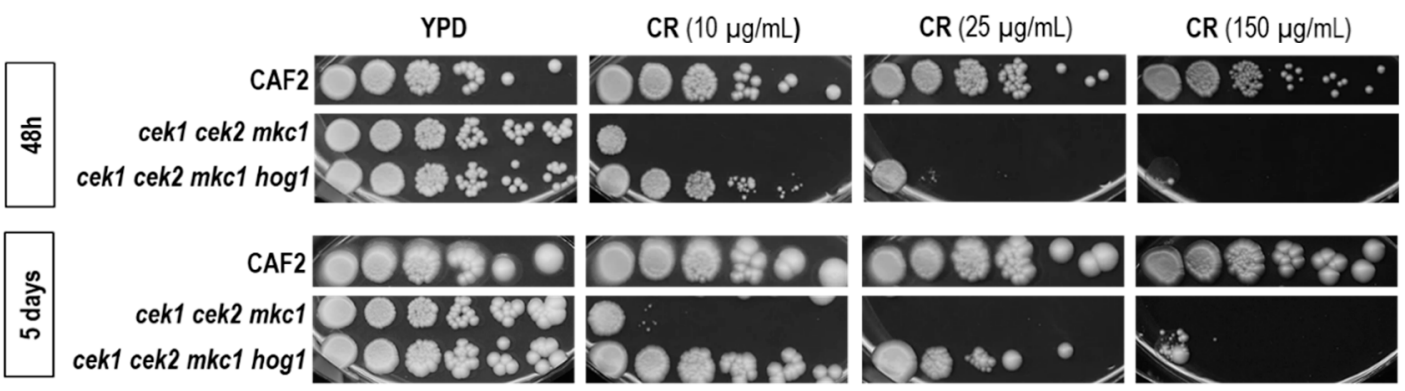

Figure 4. Comparative growth of MAPK mutants in the presence of Congo red. (A) Cells from a set of MAPK mutants from overnight grown cultures were spotted on solid agar plates of YPD medium supplemented or not (YPD-control) with different Congo red concentrations. Plates were incubated for $48 \mathrm{~h}$ at $37^{\circ} \mathrm{C}$. (B) $10^{5}$ cells and tenfold dilutions from overnight grown cultures were spotted on solid agar plates of YPD medium supplemented or not (control) with increasing concentrations of Congo red. Plates were incubated at $37^{\circ} \mathrm{C}$ for $48 \mathrm{~h}$ or five days. wt: wild type; t: triple mutants; q: quadruple mutant; i: quadruple mutants with an ectopically integrated MAPK.

In a preliminary assay with nikkomycin $\mathrm{Z}$ we were also able to assess whether the previously described resistant phenotype of hog1 strain was Cek1 dependent. This compound also targets the fungal cell wall through inhibition of chitin synthesis, acting as a competitive analogue of chitin synthase substrate UDP-N-acetylglucosamine [49]. All strains lacking the Hog1 kinase were resistant to nikkomycin Z (Figure S2) suggesting that no other MAPK is involved in counterbalancing the phenotype. Although the quadruple mutant behaved similarly to the wild type, the ectopic expression of HOG1 remarkably induced strain sensitivity to nikkomycin $\mathrm{Z}$ and an increase in resistance was observed upon integration of the other kinases. Interestingly, the deletion of CEK1 and/or CEK2 did not significantly alter the behavior of $C$. albicans in the presence of nikkomycin Z, despite their clear role in cell wall biogenesis and in the response to cell wall perturbing agents. In fact, the response to this compound seems to highly depend on Mkc1 and Hog1. According to our results, the $m k c 1$ phenotype could be caused by a compensatory mechanism involving the HOG pathway as all $m k c 1$ mutants showed a sensitive phenotype to this drug that was only reverted by the additional deletion of HOG1. This behavior was also observed in response to caspofungin [48].

\subsection{Hog1 Is the Key MAPK for C. albicans Morphological Transitions}

MAPK pathways are involved in C. albicans morphogenesis and, particularly, in the yeast-to-hypha transition. Hog1 is a well-characterized repressor of filamentation and essential for the development of chlamydospores [15,25], while Mkc1 is implicated in biofilm formation and in the morphologic 
transition to hyphae on solid medium [28,50]. Cek1 has an important role on C. albicans vegetative growth and in the dimorphic yeast-to-hypha transition in response to several stimuli [41].

We were interested in analyzing our MAPK-defective strains regarding the morphogenetic program as well as determining the complementary roles or unveiling synergies between the MAPK signaling pathways. For this purpose, we analyzed the morphology of fungal cells grown in $5 \%$ serum (under weak filament inducing conditions) or in $100 \%$ serum (strong inducing conditions) at $30^{\circ} \mathrm{C}$ in liquid media by microscopic analysis.

As shown in Figure 5, the quadruple mutant (cek1 cek2 $m k c 1$ hog 1 ) is able to filament after $5 \mathrm{~h}$ of growth in $5 \%$ serum and even on YPD medium, therefore resembling the hog 1 phenotype. The dominant repressive role of Hog1 on morphogenesis is demonstrated by the hyphal morphology presented by all hog1 mutants under non-inducing conditions (Figure 5). The deletion of CEK1 in the hog 1 background (cek1 hog1 and cek1 cek2 hog1) seems to slightly inhibit filamentation. The same is true when comparing the hog1 mkc1 with cek1 $m k c 1$ hog1 strain [48]. This was somewhat expected due to the complementary roles these two MAPKs exert on morphological transitions. All mutants analyzed were able to form hyphae as observed upon $24 \mathrm{~h}$ of growth in 100\% serum (Figure S3).

YPD
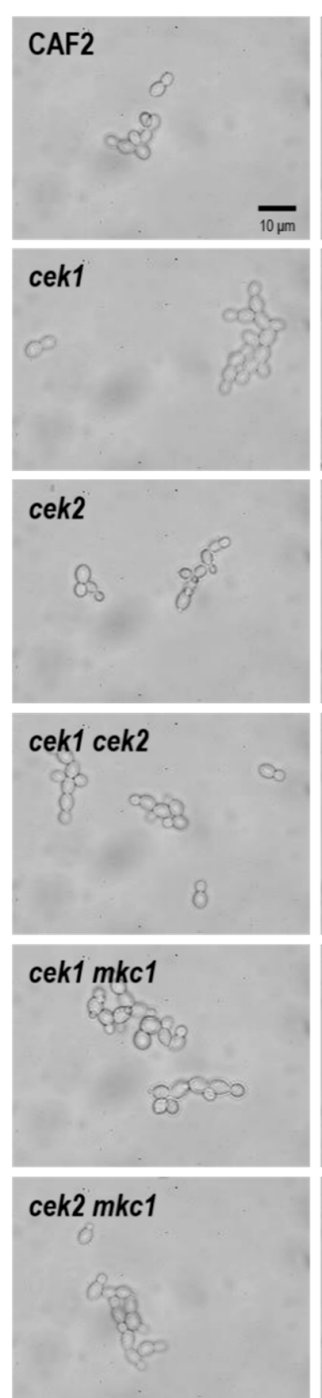

$5 \%$ serum
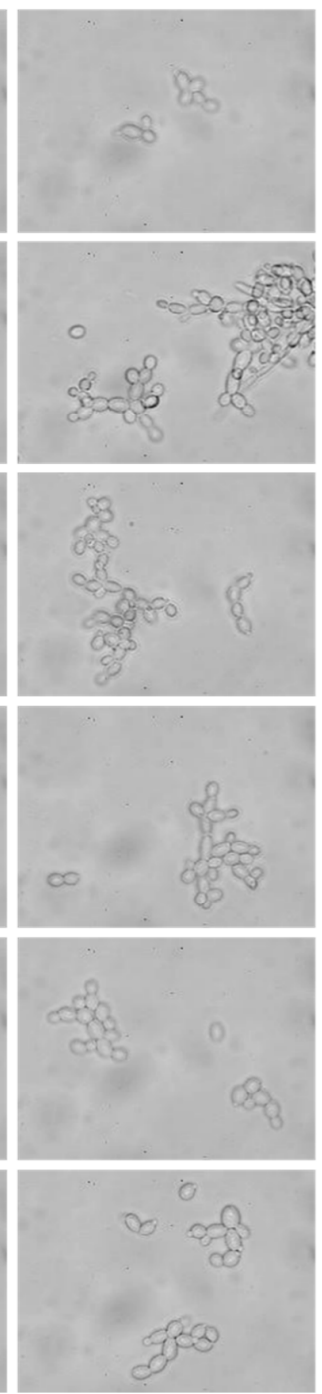

YPD
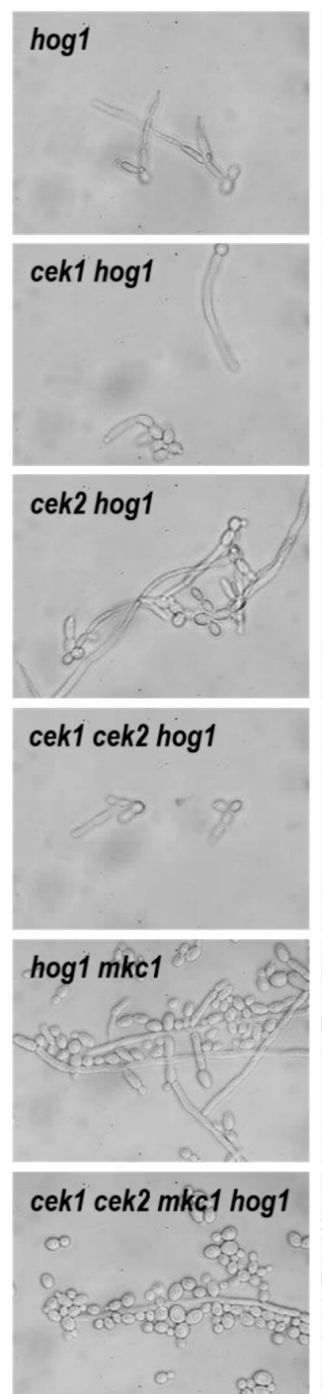

$5 \%$ serum
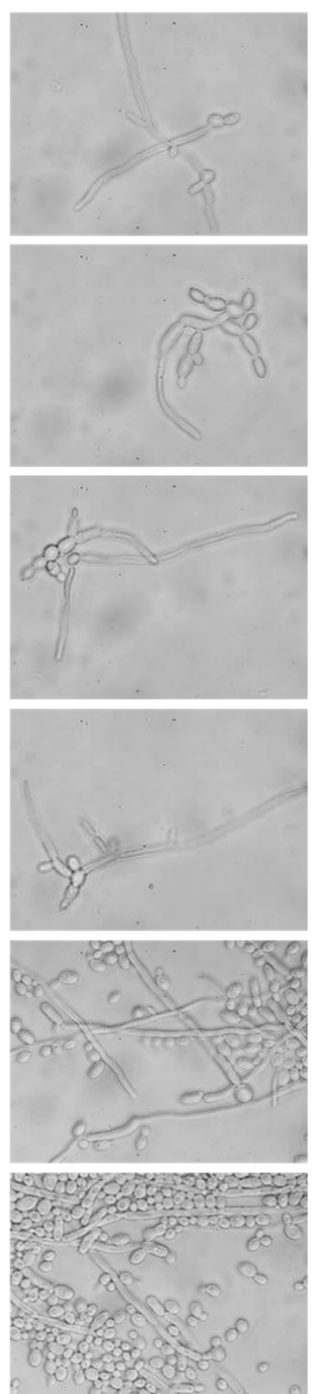

Figure 5. Yeast-to-hypha transition in liquid medium. $10^{6}$ cells from overnight cultures were inoculated in YPD medium or $5 \%$ serum. Samples were observed after $5 \mathrm{~h}$ of growth at $30^{\circ} \mathrm{C}$ and representative pictures are shown. All pictures were taken at the same magnification. Scale bar $=10 \mu \mathrm{m}$. 
We also analyzed the ability of our multiple deletion strains to generate chlamydospores (Figure 6).
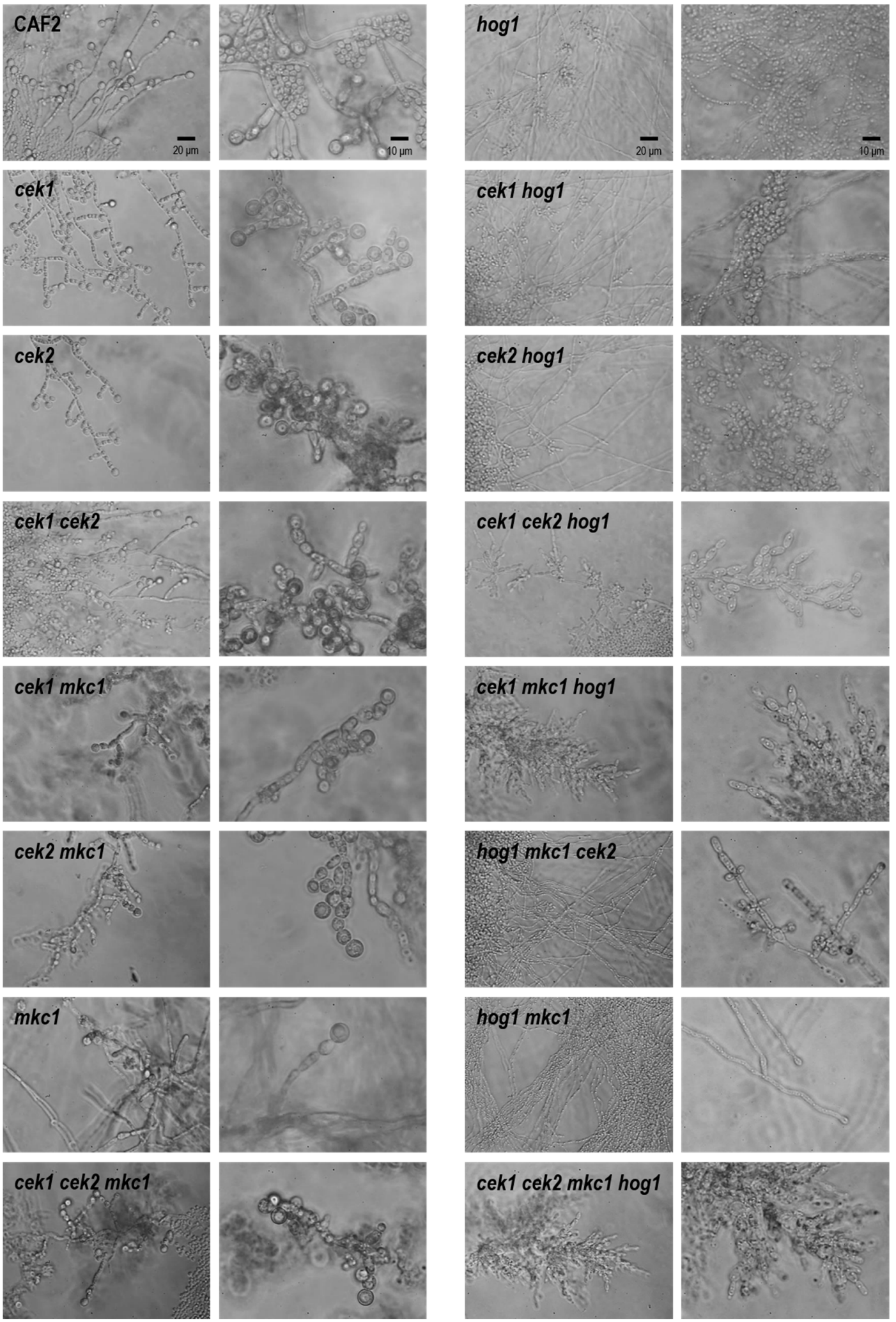

Figure 6. Twenty-five to fifty cells from stationary grown cultures were inoculated on Corn Meal Agar medium supplemented with Tween 80. Chlamydospores were observed between 4 and 7 days upon incubation at $24^{\circ} \mathrm{C}$ in dark and microaerophilic conditions. Representative pictures are shown. Pictures in the same column were taken at the same magnification. Scale bar is shown in the first row. 
Neither Cek1, Cek2 nor Mkc1 is necessary for the formation of these structures. In fact, cek2 and cek1 cek2 seem to present clusters of cells that could derive from an increased number of chlamydospores. In clear contrast, deletion of HOG1 completely abolished this morphotype, confirming previous studies that indicate the essential role of HOG1 in this process. None of the mutants in a hog1 background (including cek1 hog1, cek2 hog1 and cek1 cek2 hog1) were able to form chlamydospores, even after a prolonged incubation period and maintenance under inducing conditions (microaerophilia, low temperature and darkness). This was unexpected as the double mutant $h s t 7$ hog1, defective in Cek1/Cek2 activation, showed chlamydospore formation [38]. The quadruple mutant was unable to develop chlamydospores.

\subsection{The Absence of MAPKs Triggers White-Opaque Switching in Rich Medium in a Hog1-Dependent Manner}

During our phenotyping analysis we observed that three-day-old colonies from the quadruple mutant, grown in YPD solid medium at room temperature $\left(<21^{\circ} \mathrm{C}\right)$, presented grey sectors emerging from the white standard colonies, which potentially indicates a phenotypic switch from white-to-opaque cells. In order to confirm the presence of opaque cells amongst our colonies, we prepared cell suspensions of two independent strains defective in all four MAPKs (cek1 cek2 hog $1 m k c 1$ and cek1 cek2 mkc1 hog1) obtained from white colonies previously grown on YPD solid medium at $30^{\circ} \mathrm{C}$ (with no grey sectors). These cell suspensions were inoculated on YPD phloxine B plates (which are used to discriminate between white and opaque sectors), and pink sectors were observed after 7 days' growth at room temperature (Figure 7A), supporting the idea of a spontaneous switching. The colonial morphology of these cells resembled the opaque phenotype: flattened colonies with a matte appearance, contrasting to convex and shiny white colonies.

As opaque cells are highly unstable at physiological temperatures [51,52], mass switching of opaque cells to white cells can be induced by a temperature shift from (below) $25^{\circ} \mathrm{C}$ to $37^{\circ} \mathrm{C}$ [53]. We thus analyzed the colonies phenotype at different temperatures. Opaque cells from distinguishable dark-pink colonies of the YPD plates grown at RT were re-inoculated on fresh YPD (with phloxine B) and incubated at $37^{\circ} \mathrm{C}, 30^{\circ} \mathrm{C}$ or below $21^{\circ} \mathrm{C}(\mathrm{RT})$. The opaque state of the quadruple mutant was stable at RT as almost all colonies maintained the dark-pink coloration characteristic of this phenotype. However, previously opaque cells turned into the white phenotype at $37^{\circ} \mathrm{C}$ and no opaque colonies, nor opaque sectors, were seen even after a longer incubation period. Cells also switched back from opaque to white gradually when incubated at $30^{\circ} \mathrm{C}$ and almost every colony presented a mixture of white and opaque cells seen as perfectly differentiated colony sectors (Figure S4). White-opaque switching of the quadruple mutant was unexpected as this transition is under the control of the mating type a1 $/ \alpha 2$ repressor; we thus suspected that during the generation of the quadruple strain, a conversion to the homozygous type had occurred, probably due to the stress imposed on cells as it can promote genetic rearrangements [54]. Through PCR amplification of the MTL locus, we were able to confirm that this strain became in fact MTL a/a.

This, in turn, allowed us to better understand the contribution of each MAPK to the observed phenotype. We integrated each of the four MAPKs into the ADH1 locus of the quadruple homozygous mutant and analyzed the obtained strains for their switching ability on YPD solid medium at RT (Figure 7B). The ectopic expression of CEK1 or MKC1 did not affect switching and the presented phenotype was similar to that of the quadruple mutant $(100 \%$ of the analyzed colonies with opaque sectors). However, as evidenced in Figure 7C, the overexpression of CEK2 led to a decrease in the number of cells with opaque sectors (from $100 \%$ of the quadruple mutant to $67 \%$ ) and HOG1 ectopic expression completely abolished white-opaque switching from the quadruple mutant $(100 \%$ white colonies). These results suggest that Hog1 and Cek2 (but not Cek1 nor Mkc1) are involved in the white-opaque transition of $C$. albicans. 


\section{A}

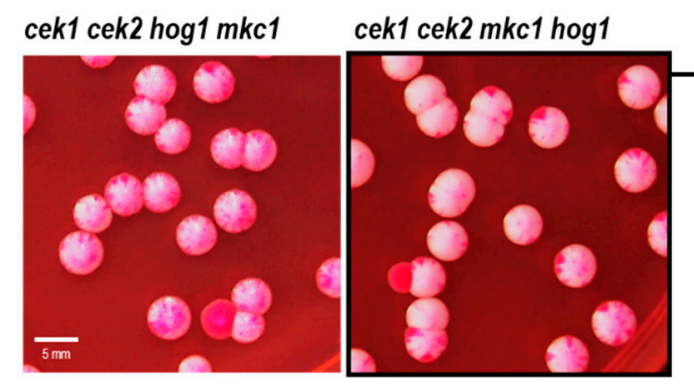

$\mathrm{C}$
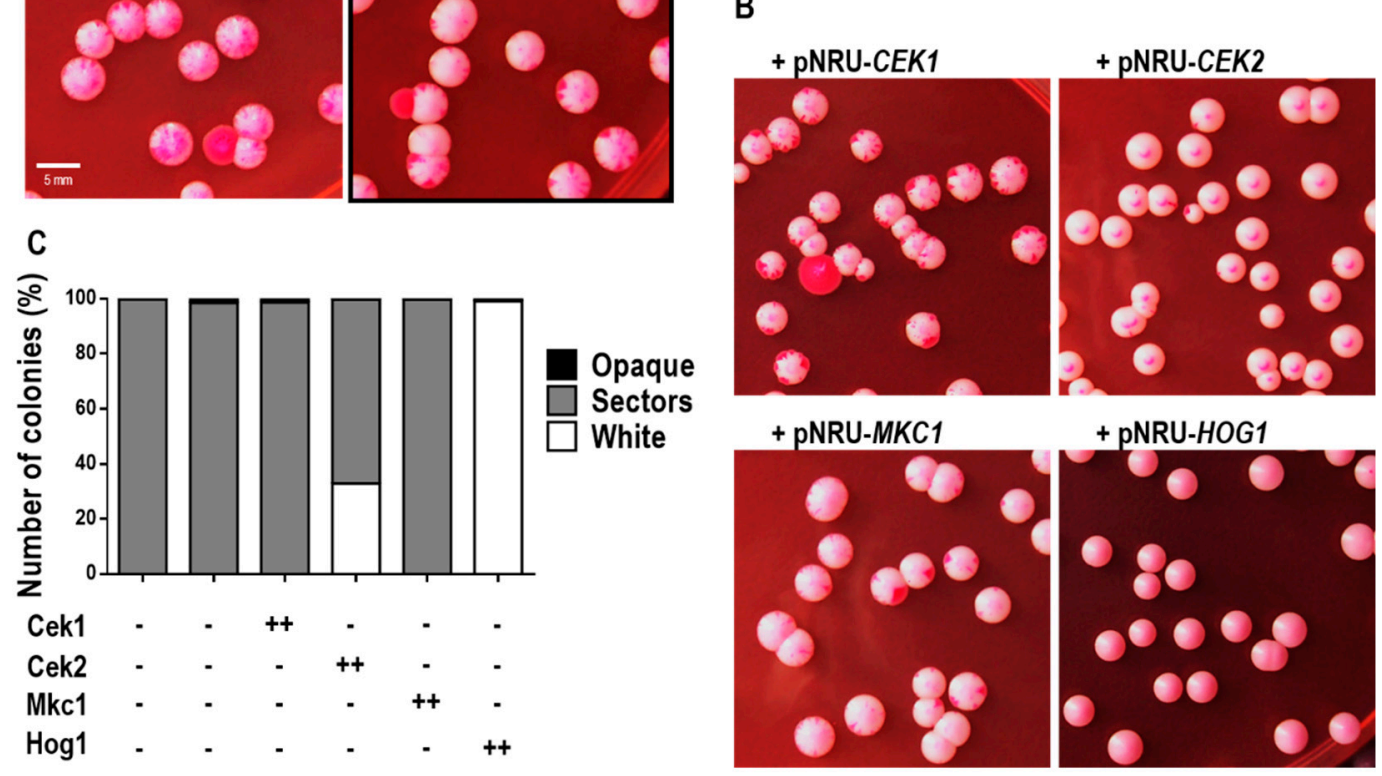

Figure 7. White-opaque switching of $C$. albicans strains lacking MAPKs. The quadruple mutant (cek1 cek2 mkc1 hog1) was transformed with the plasmid pNRU carrying the CEK1, CEK2, MKC1 or HOG1 genes and the obtained strains were analyzed. Cells from white colonies grown on YPD at $30{ }^{\circ} \mathrm{C}$ were inoculated on YPD agar plates supplemented with phloxine B. (A) and (B) Representative pictures of colonies morphology of the indicated strains, from four independent experiments, taken after 8 days growth at room temperature (RT) $\left(<21^{\circ} \mathrm{C}\right)$. (C) Summary graphic showing the percentage of white, opaque or white colonies with opaque sectors observed upon 12 days of growth at RT. At least 400 colonies from two independent experiments were analyzed. - stands for gene disruption and ++ for strains expressing ectopically (at $A D H 1$ locus) a single copy of the MAPK gene. All pictures were taken at the same magnification. Scale bar $=5 \mathrm{~mm}$.

\section{Discussion}

In this work we have generated and characterized strains defective in three or in all four major MAPKs of C. albicans, to further advance our understanding about the complex crosstalk among these pathways $[33-35,55]$. These mutants allowed us to answer two main questions: Can C. albicans survive without a functional MAPK network? Does $C$. albicans depend on a specific MAPK to respond and adapt to stress conditions and, if so, to what extent? We show here that cek1 cek $2 m k c 1$ hog1 cells are viable and show no evident growth defects under standard laboratory in vitro conditions, although they are highly sensitive to stress.

We were able to confirm the major role of Hog1 in C. albicans during oxidative and osmotic stress; cells with a functional HOG pathway are able to efficiently grow under these conditions and the ectopic expression of HOG1 in the quadruple mutant completely overcomes the sensitivity of this mutant. However, while the quadruple mutant presents the same phenotype as a hog 1 single mutant in the presence of oxidants, it displays an increased sensitivity to osmotic stress similar to what is observed in cells which are also defective in CEK1 $[37,44]$. The survival and proliferation of C. albicans under oxidative conditions on solid media is mainly dependent on Hog1, even though other kinases show altered levels of phosphorylation upon oxidative challenge [29,36,38]. Interestingly, we cannot discard the involvement of other MAPKs in the susceptibility to macrophage killing as the quadruple mutant has an increased susceptibility compared to triple and double mutations, even though hog1 is the only 
single mutant whose killing is increased compared to wild-type cells [43]. This result is in line with both the existence of multiple mechanisms involved in killing by macrophages and cell wall changes (as revealed by the accessibility to specific epitopes [31]) in these strains that may influence interactions with immune cells [56].

Oxidative stress has also been associated with the mechanism of action of amphotericin B and fluconazole $[45,46,57]$. Our results are in agreement with this, as strains defective in HOG1 (which are highly susceptible to oxidative stress), are also sensitive to these antifungals. It has recently been shown that treatment with amphotericin B results in the phosphorylation of Hog1 and that the absence of this stress kinase increases fungal susceptibility to this antifungal compound [58]. Strikingly, cek1, cek2 and cek1 cek2 double mutants were consistently less susceptible to amphotericin B. Cell wall alterations caused by the deletion of these kinases $[34,37,59]$ could alter the accessibility of the antifungal to the membrane. While we cannot discard this, we are more inclined to the hypothesis of a more permeable, loose, and weakened cell wall in cek1/2 mutants.

The C. albicans hog1 strain is more resistant than the wild type to compounds that affect the fungal cell wall, such as Congo red, nikkomycin $\mathrm{z}$ and to a lesser extent to calcofluor white [25]. This is consistent with the role of the HOG pathway in controlling (at least partially) chitin synthesis [60] and to the sustained activation of the Cek1 kinase observed in hog1 mutants $[29,61]$. In fact, the deletion of HST7 (Cek1 MAPK kinase) or CEK1 itself (but not CEK2) in a hog1 background suppressed the resistant phenotype [37,38]. However, when analyzing strains defective in three or four MAPKs, we were able to reveal the putative existence of a Cek1-independent mechanism to explain hog1 resistance to cell wall interfering compounds. First, deletion of HOG1 alleviates the Congo red hypersensitivity caused by the absence of a functional Cek1/Cek2 and Mkc1 pathways and the ectopic expression of Hog1 in the quadruple mutant increases its sensitivity. Second, the deletion of CEK1 in strains with a hog1 background was not sufficient to suppress their resistant phenotype to nikkomycin Z. Therefore, other elements or mechanisms, besides Cek1 hyperactivation, may be implicated in resistance of the hog1 mutant to cell wall perturbing agents. The same is true for chlamydospore formation as none of the strains defective in Hog1 kinase were able to form chlamydospores. It has been suggested that Hog1 would have an inducing role on this phenotype through the hyperactivation of Cek1 due to the wild-type-like phenotype displayed by the hog1 hst7 strain [38]; however, this hypothesis could not be tested at the time due to the lack of a cek1 hog1 double mutant. Our results support a critical role for Hog1-discarding any evident role for Cek1, Cek2 and Mkc1-in the formation of chlamydospores.

Our results also confirm a major role for HOG1 in repressing hyphal formation as all mutants with a HOG1 deletion were shown to filament in non-inducing (or mildly-inducing-) conditions. Such effects have been described to be dependent on the TOR pathway, which connects nutrient sensing and MAPK signaling. Under low nutrient availability, specific tyrosine phosphatases dephosphorylate and thus deactivate Hog1, which in turn suppresses the potential of Hog1 to repress hyphal elongation; this process occurs via dissociation of the Sko1 complex from the promoter of Brg1, a positive regulator of filamentation [62]. Coherently, strains defective in elements from the HOG pathway express Brg1 independently of rapamycin. Our data also indicate that none of the MAPKs, either alone or in combination, are essential for the dimorphic transition under serum, inducing conditions which may be relevant to disseminated infection. This is consistent with the involvement of several pathways in the dimorphic transition [63] and the apparent redundancy between them.

cek1 cek $2 \mathrm{mkc1}$ hog 1 mutants were able to undergo white-opaque switching with high frequency on YPD medium. This transition occurred at low temperature $\left(<21^{\circ} \mathrm{C}\right)$ and without any other specific environmental requirement. The involvement of MAPK signaling in this process makes sense in the context of their role as sensor mechanisms of the environment. In fact, environmental conditions seem to substantially regulate white-opaque switching. Its efficiency and the stability of the opaque phenotype is highly affected by temperature $[51,52,64]$, by the level of $\mathrm{CO}_{2}[65,66]$, by the sugar source [67] and also by genotoxic and oxidative stress [68], UV radiation, in vitro oxidants and white blood cell metabolites [69]. Some of these stimuli are known to trigger activation of MAPKs and 
it is therefore conceivable that evolution has coupled MAPK cascades to enable a precise timing of white-opaque switching. In fact, recent reports have shown that hog1 mutants in a/a background (homozygous for MTL), as well as other strains defective in upstream elements of the HOG pathway, display an increased switching phenotype that is dependent on Wor1 [70,71], the master regulator of white-opaque switching [72,73]. We were able to confirm this observation as the ectopic expression of Hog1 in cek1 cek $2 m k c 1$ hog1 cells completely abolished the opaque state of this strain. We were also able to implicate, at least partially, Cek2 (but not Cek1) in this process. It is surprising and unexpected that the expression of $C E K 1$ in a quadruple mutant did not block the formation of opaque sectors. Ramírez-Zavala and co-workers have assessed the switching frequency of a mating competent strain (WO-1-MTL $\alpha / \alpha)$ overexpressing a hyperactive allele of Ste11 [74], the MAPK kinase kinase of the Cek1/Cek2 mediated pathway. The white-opaque switching is increased in this strain, by an unknown physiological signal that is transmitted along the pathway and it was shown to require the downstream MAPK Cek1 (but not Cek2) and its target transcription factor Cph1. Even though certain a/ $\alpha$ strains (heterozygous for MTL) are capable of white-opaque switching [75], homozygosis still seems to be an important requirement for this process. The epigenetic switch is controlled by Wor1 (amongst other transcription factors) whose expression is repressed by MTL a1/ $\alpha 2$ repressor and thus the phenotypic transition, as well as mating, is inhibited in cells heterozygous for the MTL locus. This is consistent with the fact that the minority of natural isolates capable of undergoing the white-opaque switch in vitro were found to be a/a or $\alpha / \alpha[19,73,76]$. Our results confirm that HOG1 is the main kinase involved in white-opaque switching but also reveal a role for Cek2 (but not Cek1) in this process. Functional differences between Cek1 and Cek2 have been detected by our group [37], and recently it has been shown that the phosphorylation and nuclear localization in response to pheromone is different between both kinases [77].

Our newly described cek1 cek2 $m k c 1$ hog1 strain is an interesting and powerful tool in different areas of research. As a strain completely devoid of MAPKs could be used to perform synthetic biology studies with mammalian or other fungal MAPKs. Given its likely lack of virulence in animal hosts (all hog1, cek1 and $m k c 1$ show reduced virulence in the mouse systemic animal model) $[15,27,31,41]$ ), it could potentially be used as an attenuated live vaccine. Finally, we envision that it will be also an attractive tool for the analysis of genetic recombination in this fungus induced by stress [22], a phenomenon that seems to be of great clinical significance [78].

Supplementary Materials: The following are available online at http://www.mdpi.com/2309-608X/6/4/230/s1, Figure S1: Analysis of gene disruption through Southern blot.; Figure S2: Sensitivity of MAPK mutants to nikkomycin Z.; Figure S3: Yeast-to-hypha transition in 100\% serum. Figure S4: Opaque-white switching of cek1 cek2 mkc1 hog1 upon incubation at different temperatures.

Author Contributions: Conceptualization, I.C., J.P., D.W., B.H.; methodology, I.C.; validation, I.C.; resources, J.P.; data curation, I.C., J.P.; writing—original draft preparation, I.C., J.P.; writing-review and editing, D.W., B.H.; funding acquisition, J.P. All authors have read and agreed to the published version of the manuscript.

Funding: Work in our laboratory is funded by PGC2018-095047-B-I00 fromMINECO (Ministerio de Economía y Competitividad, Spain) and S2017/BMD-3691 InGEMICS-CM from Comunidad Autónoma de Madrid. D.W. is supported by a Wellcome Trust Senior Research Fellowship [214317/A/18/Z]; a Wellcome Trust Strategic Award for Medical Mycology and Fungal Immunology [09 7377/Z/11/Z]; the Medical Research Council (MRC) and University of Exeter [MR/N006364/2].

Conflicts of Interest: The authors declare no conflict of interest.

\section{References}

1. Pfaller, M.A.; Diekema, D.J.; Turnidge, J.D.; Castanheira, M.; Jones, R.N. Twenty Years of the SENTRY Antifungal Surveillance Program: Results for Candida Species From 1997-2016. Open forum Infect. Dis. 2019, 6, S79-S94. [CrossRef] [PubMed]

2. Pfaller, M.A.; Diekema, D.J. Epidemiology of invasive candidiasis: A persistent public health problem. Clin. Microbiol. Rev. 2007, 20, 133-163. [CrossRef] [PubMed] 
3. Brown, G.D.; Denning, D.W.; Gow, N.A.R.; Levitz, S.M.; Netea, M.G.; White, T.C. Hidden killers: Human fungal infections. Sci. Transl. Med. 2012, 4, 165rv113. [CrossRef]

4. Lo, H.J.; Kohler, J.R.; DiDomenico, B.; Loebenberg, D.; Cacciapuoti, A.; Fink, G.R. Nonfilamentous Candida albicans mutants are avirulent. Cell 1997, 90, 939-949. [CrossRef]

5. Saville, S.P.; Lazzell, A.L.; Monteagudo, C.; Lopez-Ribot, J.L. Engineered control of cell morphology in vivo reveals distinct roles for yeast and filamentous forms of Candida albicans during infection. Eukaryot. Cell 2003, 2, 1053-1060. [CrossRef] [PubMed]

6. Ghosh, S.; Navarathna, D.H.; Roberts, D.D.; Cooper, J.T.; Atkin, A.L.; Petro, T.M.; Nickerson, K.W. Arginine-induced germ tube formation inCandida albicans is essential for escape from murine macrophage line RAW 264.7. Infect. Immun. 2009, 77, 1596-1605. [CrossRef]

7. Gantner, B.N.; Simmons, R.M.; Underhill, D.M. Dectin-1 mediates macrophage recognition of Candida albicans yeast but not filaments. EMBO J. 2005, 24, 1277-1286. [CrossRef]

8. Saville, S.P.; Lazzell, A.L.; Chaturvedi, A.K.; Monteagudo, C.; Lopez-Ribot, J.L. Use of a genetically engineered strain to evaluate the pathogenic potential of yeast cell and filamentous forms during Candida albicans systemic infection in immunodeficient mice. Infect. Immun. 2008, 76, 97-102. [CrossRef]

9. Dujardin, L.; Walbaum, S.; Biguet, J. Effect of glucose and nitrogen concentrations on the morphology of Candida albicans and the formation of chlamydospores in synthetic culture media. Mycopathologia 1980, 71, 113-118. [CrossRef]

10. Montazeri, M.; Hedrick, H.G. Factors affecting spore formation in a Candida albicans strain. Appl. Environ. Microbiol. 1984, 47, 1341-1342. [CrossRef]

11. Jansons, V.K.; Nickerson, W.J. Induction, morphogenesis, and germination of the chlamydospore of Candida albicans. J. Bacteriol. 1970, 104, 910-921. [CrossRef] [PubMed]

12. Odds, F.C. Candida and candidosis; Baillière Tindall: London, UK, 1988; Vol. 2.

13. Citiulo, F.; Moran, G.P.; Coleman, D.C.; Sullivan, D.J. Purification and germination of Candida albicans and Candida dubliniensis chlamydospores cultured in liquid media. FEMS Yeast Res. 2009, 9, 1051-1060. [CrossRef]

14. Sonneborn, A.; Bockmuhl, D.P.; Ernst, J.F. Chlamydospore formation in Candida albicans requires the Efg1p morphogenetic regulator. Infect. Immun. 1999, 67, 5514-5517. [CrossRef] [PubMed]

15. Alonso-Monge, R.; Navarro-Garcia, F.; Román, E.; Negredo, A.I.; Eisman, B.; Nombela, C.; Pla, J. The Hog1 mitogen-activated protein kinase is essential in the oxidative stress response and chlamydospore formation in Candida albicans. Eukaryot. Cell 2003, 2, 351-361. [CrossRef]

16. Palige, K.; Linde, J.; Martin, R.; Bottcher, B.; Citiulo, F.; Sullivan, D.J.; Weber, J.; Staib, C.; Rupp, S.; Hube, B.; et al. Global transcriptome sequencing identifies chlamydospore specific markers in Candida albicans and Candida dubliniensis. PLoS ONE 2013, 8, e61940. [CrossRef] [PubMed]

17. Miller, M.G.; Johnson, A.D. White-opaque switching in Candida albicans is controlled by mating-type locus homeodomain proteins and allows efficient mating. Cell 2002, 110, 293-302. [CrossRef]

18. Lockhart, S.R.; Daniels, K.J.; Zhao, R.; Wessels, D.; Soll, D.R. Cell biology of mating in Candida albicans. Eukaryot. Cell 2003, 2, 49-61. [CrossRef] [PubMed]

19. Lockhart, S.R.; Pujol, C.; Daniels, K.J.; Miller, M.G.; Johnson, A.D.; Pfaller, M.A.; Soll, D.R. In Candida albicans, white-opaque switchers are homozygous for mating type. Genetics 2002, 162, 737-745. [PubMed]

20. Soll, D.R. The role of phenotypic switching in the basic biology and pathogenesis of Candida albicans. J. Oral Microbiol. 2014, 6. [CrossRef]

21. Ene, I.V.; Bennett, R.J.; Anderson, M.Z. Mechanisms of genome evolution in Candida albicans. Curr. Opin. Microbiol. 2019, 52, 47-54. [CrossRef]

22. Forche, A.; Abbey, D.; Pisithkul, T.; Weinzierl, M.A.; Ringstrom, T.; Bruck, D.; Petersen, K.; Berman, J. Stress alters rates and types of loss of heterozygosity in Candida albicans. MBio 2011, 2. [CrossRef]

23. Forche, A.; Magee, P.T.; Selmecki, A.; Berman, J.; May, G. Evolution in Candida albicans populations during a single passage through a mouse host. Genetics 2009, 182, 799-811. [CrossRef]

24. Ropars, J.; Maufrais, C.; Diogo, D.; Marcet-Houben, M.; Perin, A.; Sertour, N.; Mosca, K.; Permal, E.; Laval, G.; Bouchier, C.; et al. Gene flow contributes to diversification of the major fungal pathogen Candida albicans. Nat. Commun. 2018, 9, 2253. [CrossRef] [PubMed] 
25. Alonso-Monge, R.; Navarro-García, F.; Molero, G.; Díez-Orejas, R.; Gustin, M.; Pla, J.; Sánchez, M.; Nombela, C. Role of the mitogen-activated protein kinase Hog1p in morphogenesis and virulence of Candida albicans. J. Bacteriol. 1999, 181, 3058-3068. [CrossRef]

26. San José, C.; Alonso-Monge, R.; Pérez-Díaz, R.M.; Pla, J.; Nombela, C. The mitogen-activated protein kinase homolog HOG1 gene controls glycerol accumulation in the pathogenic fungus Candida albicans. J. Bacteriol. 1996, 178, 5850-5852. [CrossRef]

27. Navarro-García, F.; Sanchez, M.; Pla, J.; Nombela, C. Functional characterization of the MKC1 gene of Candida albicans, which encodes a mitogen-activated protein kinase homolog related to cell integrity. Mol. Cell. Biol. 1995, 15, 2197-2206. [CrossRef]

28. Kumamoto, C.A. A contact-activated kinase signals Candida albicans invasive growth and biofilm development. Proc. Natl. Acad. Sci. USA 2005, 102, 5576-5581. [CrossRef]

29. Román, E.; Nombela, C.; Pla, J. The Sho1 adaptor protein links oxidative stress to morphogenesis and cell wall biosynthesis in the fungal pathogen Candida albicans. Mol. Cell. Biol. 2005, 25, 10611-10627. [CrossRef]

30. Román, E.; Alonso-Monge, R.; Gong, Q.; Li, D.; Calderone, R.; Pla, J. The Cek1 MAPK is a short-lived protein regulated by quorum sensing in the fungal pathogen Candida albicans. FEMS Yeast Res. 2009, 9, 942-955. [CrossRef] [PubMed]

31. Román, E.; Correia, I.; Salazin, A.; Fradin, C.; Jouault, T.; Poulain, D.; Liu, F.T.; Pla, J. The Cek1-mediated MAP kinase pathway regulates exposure of $\alpha-(1,2)$ and $\beta-(1,2)$-mannosides in the cell wall of Candida albicans modulating immune recognition. Virulence 2016, 7, 558-577. [CrossRef] [PubMed]

32. Chen, J.; Chen, J.; Lane, S.; Liu, H. A conserved mitogen-activated protein kinase pathway is required for mating in Candida albicans. Mol. Microbiol. 2002, 46, 1335-1344. [CrossRef]

33. Román, E.; Correia, I.; Prieto, D.; Alonso, R.; Pla, J. The HOG MAPK pathway in Candida albicans: More than an osmosensing pathway. Int. Microbiol. 2019. [CrossRef]

34. Correia, I.; Prieto, D.; Román, E.; Wilson, D.; Hube, B.; Alonso-Monge, R.; Pla, J. Cooperative Role of MAPK Pathways in the Interaction of Candida albicans with the Host Epithelium. Microorganisms 2019, 8. [CrossRef] [PubMed]

35. Román, E.; Arana, D.M.; Nombela, C.; Alonso-Monge, R.; Pla, J. MAP kinase pathways as regulators of fungal virulence. Trends Microbiol. 2007, 15, 181-190. [CrossRef] [PubMed]

36. Navarro-García, F.; Eisman, B.; Fiuza, S.M.; Nombela, C.; Pla, J. The MAP kinase Mkc1p is activated under different stress conditions in Candida albicans. Microbiology 2005, 151, 2737-2749. [CrossRef] [PubMed]

37. Correia, I.; Román, E.; Prieto, D.; Eisman, B.; Pla, J. Complementary roles of the Cek1 and Cek2 MAP kinases in Candida albicans cell-wall biogenesis. Future Microbiol. 2016, 11, 51-67. [CrossRef] [PubMed]

38. Eisman, B.; Alonso-Monge, R.; Román, E.; Arana, D.M.; Nombela, C.; Pla, J. The Cek1 and Hog1 mitogen-activated protein kinases play complementary roles in cell wall biogenesis and chlamydospore formation in the fungal pathogen Candida albicans. Eukaryot. Cell 2006, 5, 347-358. [CrossRef]

39. Fonzi, W.A.; Irwin, M.Y. Isogenic strain construction and gene mapping in Candida albicans. Genetics 1993, 134, 717-728.

40. Gillum, A.M.; Tsay, E.Y.H.; Kirsch, D.R. Isolation of the Candida albicans gene for orotidine-5'- phosphate decarboxylase by complementation of S. cerevisiae ura3 and E. coli pyrF mutations. Mol. Gen. Genet. 1984, 198, 179-182. [CrossRef] [PubMed]

41. Csank, C.; Schröppel, K.; Leberer, E.; Harcus, D.; Mohamed, O.; Meloche, S.; Thomas, D.Y.; Whiteway, M. Roles of the Candida albicans mitogen-activated protein kinase homolog, Cek1p, in hyphal development and systemic candidiasis. Infect. Immun. 1998, 66, 2713-2721. [CrossRef] [PubMed]

42. Prieto, A.D.; Román, E.; Correia, I.; Pla, J. The HOG pathway is critical for the colonization of the mouse gastrointestinal tract by Candida albicans. PLoS ONE 2014, 9, e87128. [CrossRef] [PubMed]

43. Arana, D.M.; Alonso-Monge, R.; Du, C.; Calderone, R.; Pla, J. Differential susceptibility of mitogen-activated protein kinase pathway mutants to oxidative-mediated killing by phagocytes in the fungal pathogen Candida albicans. Cell. Microbiol. 2007, 9, 1647-1659. [CrossRef]

44. Herrero-de-Dios, C.; Alonso-Monge, R.; Pla, J. The lack of upstream elements of the Cek1 and Hog1 mediated pathways leads to a synthetic lethal phenotype upon osmotic stress in Candida albicans. Fungal Genet. Biol. 2014, 69, 31-42. [CrossRef] [PubMed] 
45. Kobayashi, D.; Kondo, K.; Uehara, N.; Otokozawa, S.; Tsuji, N.; Yagihashi, A.; Watanabe, N. Endogenous reactive oxygen species is an important mediator of miconazole antifungal effect. Antimicrob. Agents Chemother. 2002, 46, 3113-3117. [CrossRef]

46. Mesa-Arango, A.C.; Trevijano-Contador, N.; Román, E.; Sanchez-Fresneda, R.; Casas, C.; Herrero, E.; Arguelles, J.C.; Pla, J.; Cuenca-Estrella, M.; Zaragoza, O. The production of reactive oxygen species is a universal action mechanism of Amphotericin B against pathogenic yeasts and contributes to the fungicidal effect of this drug. Antimicrob. Agents Chemother. 2014, 58, 6627-6638. [CrossRef] [PubMed]

47. Román, E.; Prieto, D.; Martin, R.; Correia, I.; Mesa Arango, A.C.; Alonso-Monge, R.; Zaragoza, O.; Pla, J. Role of catalase overproduction in drug resistance and virulence in Candida albicans. Future Microbiol. 2016, 11, 1279-1297. [CrossRef]

48. Correia, I. Role of the Cek1 and Cek2 kinases within the MAPK signalling network of the fungal pathogen Candida albicans. Ph.D. Thesis, Universidad Complutense de Madrid, Facultad de Farmacia, Madrid, Spain, 2014.

49. Cabib, E. Differential inhibition of chitin synthetases 1 and 2 from Saccharomyces cerevisiae by polyoxin D and nikkomycins. Antimicrob. Agents Chemother. 1991, 35, 170-173. [CrossRef] [PubMed]

50. Navarro-García, F.; Alonso-Monge, R.; Rico, H.; Pla, J.; Sentandreu, R.; Nombela, C. A role for the MAP kinase gene $M K C 1$ in cell wall construction and morphological transitions in Candida albicans. Microbiology 1998, 144, 411-424. [CrossRef]

51. Slutsky, B.; Staebell, M.; Anderson, J.; Risen, L.; Pfaller, M.; Soll, D.R. “White-opaque transition”: A second high-frequency switching system in Candida albicans. J. Bacteriol. 1987, 169, 189-197. [CrossRef]

52. Rikkerink, E.H.; Magee, B.B.; Magee, P.T. Opaque-white phenotype transition: A programmed morphological transition in Candida albicans. J. Bacteriol. 1988, 170, 895-899. [CrossRef]

53. Soll, D.R.; Morrow, B.; Srikantha, T. High-frequency phenotypic switching in Candida albicans. Trends Genet. 1993, 9, 61-65. [CrossRef]

54. Rosenberg, S.M. Stress-induced loss of heterozygosity in Candida: A possible missing link in the ability to evolve. MBio 2011, 2. [CrossRef]

55. Day, A.M.; Quinn, J. Stress-Activated Protein Kinases in Human Fungal Pathogens. Front. Cell Infect. Microbiol. 2019, 9, 261. [CrossRef]

56. Pradhan, A.; Avelar, G.M.; Bain, J.M.; Childers, D.; Pelletier, C.; Larcombe, D.E.; Shekhova, E.; Netea, M.G.; Brown, G.D.; Erwig, L.; et al. Non-canonical signalling mediates changes in fungal cell wall PAMPs that drive immune evasion. Nat. Commun. 2019, 10, 5315. [CrossRef]

57. Sokol-Anderson, M.L.; Brajtburg, J.; Medoff, G. Amphotericin B-induced oxidative damage and killing of Candida albicans. J. Infect. Dis. 1986, 154, 76-83. [CrossRef] [PubMed]

58. Guirao-Abad, J.P.; Sanchez-Fresneda, R.; Roman, E.; Pla, J.; Arguelles, J.C.; Alonso-Monge, R. The MAPK Hog1 mediates the response to amphotericin B in Candida albicans. Fungal Genet. Biol. 2020, 136, 103302. [CrossRef] [PubMed]

59. Galan-Diez, M.; Arana, D.M.; Serrano-Gomez, D.; Kremer, L.; Casasnovas, J.M.; Ortega, M.; Cuesta-Dominguez, A.; Corbi, A.L.; Pla, J.; Fernandez-Ruiz, E. Candida albicans beta-glucan exposure is controlled by the fungal CEK1-mediated mitogen-activated protein kinase pathway that modulates immune responses triggered through dectin-1. Infect. Immun. 2010, 78, 1426-1436. [CrossRef] [PubMed]

60. Munro, C.A.; Selvaggini, S.; de, B.I.; Walker, L.; Lenardon, M.D.; Gerssen, B.; Milne, S.; Brown, A.J.; Gow, N.A. The PKC, HOG and $\mathrm{Ca}^{2+}$ signalling pathways co-ordinately regulate chitin synthesis in Candida albicans. Mol. Microbiol. 2007, 63, 1399-1413. [CrossRef] [PubMed]

61. Arana, D.M.; Nombela, C.; Alonso-Monge, R.; Pla, J. The Pbs2 MAP kinase kinase is essential for the oxidative-stress response in the fungal pathogen Candida albicans. Microbiology 2005, 151, 1033-1049. [CrossRef]

62. Su, C.; Lu, Y.; Liu, H. Reduced TOR signaling sustains hyphal development in Candida albicans by lowering Hog1 basal activity. Mol. Biol. Cell 2013, 24, 385-397. [CrossRef]

63. Biswas, S.; Van Dijck, P.; Datta, A. Environmental sensing and signal transduction pathways regulating morphopathogenic determinants of Candida albicans. Microbiol. Mol. Biol. Rev. 2007, 71, 348-376. [CrossRef] [PubMed]

64. Srikantha, T.; Soll, D.R. A white-specific gene in the white-opaque switching system of Candida albicans. Gene 1993, 131, 53-60. [CrossRef] 
65. Ramirez-Zavala, B.; Reuss, O.; Park, Y.N.; Ohlsen, K.; Morschhauser, J. Environmental induction of white-opaque switching in Candida albicans. PLoS Path. 2008, 4, e1000089. [CrossRef]

66. Huang, G.; Srikantha, T.; Sahni, N.; Yi, S.; Soll, D.R. $\mathrm{CO}_{2}$ regulates white-to-opaque switching in Candida albicans. Curr. Biol. 2009, 19, 330-334. [CrossRef] [PubMed]

67. Huang, G.; Yi, S.; Sahni, N.; Daniels, K.J.; Srikantha, T.; Soll, D.R. N-acetylglucosamine induces white to opaque switching, a mating prerequisite in Candida albicans. PLoS Path. 2010, 6, e1000806. [CrossRef]

68. Alby, K.; Schaefer, D.; Bennett, R.J. Homothallic and heterothallic mating in the opportunistic pathogen Candida albicans. Nature 2009, 460, 890-893. [CrossRef]

69. Kolotila, M.P.; Diamond, R.D. Effects of neutrophils and in vitro oxidants on survival and phenotypic switching of Candida albicans WO-1. Infect. Immun. 1990, 58, 1174-1179. [CrossRef]

70. Liang, S.H.; Cheng, J.H.; Deng, F.S.; Tsai, P.A.; Lin, C.H. A novel function for Hog1 stress-activated protein kinase in controlling white-opaque switching and mating in Candida albicans. Eukaryot. Cell 2014, 13, 1557-1566. [CrossRef]

71. Chang, W.H.; Liang, S.H.; Deng, F.S.; Lin, C.H. The conserved dual phosphorylation sites of the Candida albicans Hog1 protein are crucial for white-opaque switching, mating, and pheromone-stimulated cell adhesion. Med Mycol. J. 2016. [CrossRef]

72. Zordan, R.E.; Miller, M.G.; Galgoczy, D.J.; Tuch, B.B.; Johnson, A.D. Interlocking transcriptional feedback loops control white-opaque switching in Candida albicans. PLoS Biol. 2007, 5, e256. [CrossRef]

73. Srikantha, T.; Borneman, A.R.; Daniels, K.J.; Pujol, C.; Wu, W.; Seringhaus, M.R.; Gerstein, M.; Yi, S.; Snyder, M.; Soll, D.R. TOS9 regulates white-opaque switching in Candida albicans. Eukaryot. Cell 2006, 5, 1674-1687. [CrossRef]

74. Ramirez-Zavala, B.; Weyler, M.; Gildor, T.; Schmauch, C.; Kornitzer, D.; Arkowitz, R.; Morschhauser, J. Activation of the Cph1-dependent MAP kinase signaling pathway induces white-opaque switching in Candida albicans. PLoS Path. 2013, 9, e1003696. [CrossRef] [PubMed]

75. Xie, J.; Tao, L.; Nobile, C.J.; Tong, Y.; Guan, G.; Sun, Y.; Cao, C.; Hernday, A.D.; Johnson, A.D.; Zhang, L.; et al. White-opaque switching in natural MTLa/alpha isolates of Candida albicans: Evolutionary implications for roles in host adaptation, pathogenesis, and sex. PLoS Biol. 2013, 11, e1001525. [CrossRef] [PubMed]

76. Huang, G.; Wang, H.; Chou, S.; Nie, X.; Chen, J.; Liu, H. Bistable expression of WOR1, a master regulator of white-opaque switching in Candida albicans. Proc. Natl. Acad. Sci. USA 2006, 103, 12813-12818. [CrossRef]

77. Rastghalam, G.; Omran, R.P.; Alizadeh, M.; Fulton, D.; Mallick, J.; Whiteway, M. MAP Kinase Regulation of the Candida albicans Pheromone Pathway. mSphere 2019, 4. [CrossRef]

78. Selmecki, A.M.; Dulmage, K.; Cowen, L.E.; Anderson, J.B.; Berman, J. Acquisition of aneuploidy provides increased fitness during the evolution of antifungal drug resistance. PLoS Genet. 2009, 5, e1000705. [CrossRef] [PubMed]

Publisher's Note: MDPI stays neutral with regard to jurisdictional claims in published maps and institutional affiliations.

(C) 2020 by the authors. Licensee MDPI, Basel, Switzerland. This article is an open access article distributed under the terms and conditions of the Creative Commons Attribution (CC BY) license (http://creativecommons.org/licenses/by/4.0/). 